\title{
APPROXIMATION BY A KANTOROVICH VARIANT OF THE BLEIMANN, BUTZER AND HAHN OPERATORS
}

\author{
Xiao-Ming Zeng ${ }^{1}$, Ulrich Abel and Mircea IVAN
}

\begin{abstract}
We study the approximation properties of a Kantorovich variant of the Bleimann, Butzer and Hahn operators for locally bounded functions, and estimate their rate of convergence by some techniques of probability theory and analysis methods.
\end{abstract}

Mathematics subject classification (2000): 41A36, 41A25, 41A10.

Key words and phrases: Bleimann, Butzer and Hahn Operators, rate of convergence, probabilistic methods, Kantorovich variant, basis functions and moments.

\section{REFERENCES}

[1] U. ABEL AND M. Ivan, Some identities for the operator of Bleimann, Butzer and Hahn involving divided differences, Calcolo 36 (1999), 143-160.

[2] U. ABEL AND M. IVAN, A Kantorovich variant of the Bleimann, Butzer and Hahn operators, Proceedings of the 4th international conference on functional analysis and approximation theory, Acquafredda di Maratea (Potenza), Italy, September 22-28, 2000: Circolo Matemàtico di Palermo, Suppl. Rend. Circ. Mat. Palermo, I. Ser. 68 (2002), 205-218.

[3] F. Altomare AND M. CAMPITI, Korovkin-type approximation theory and its applications, de Gruyter, Berlin, New York, 1994.

[4] G. Bleimann, P. L. Butzer, And L. Hahn. A Bernstein-type operator approximating continuous functions on the semi-axis, Indag. Math. 42 (1980), 255-262.

[5] R. BOJANIC AND F. CHENG, Rate of convergence of Bernstein polynomials for functions with derivative of bounded variation, J. Math. Anal. Appl. 141 (1989), 136-151.

[6] R. A. Devore And G. G. LoRentZ, Constructive Approximation, Springer Verlag, Berlin, Heidelberg, New York, 1993.

[7] W. FeLLER, An Introduction to Probability Theory and Its Applications, John Wiley \& Sons, Inc., New York, London, Toronto, 1971.

[8] T. HERMANN, On the operator of Bleimann, Butzer and Hahn, in: J. Szabados and K. Tandori, editors, Approximation Theory, Colloquia Mathematica Societatis János Bolyai, North-Holland Publishing Company, Volume 58 (1990), 355-360.

[9] C. JAYASRI AND Y. SitARAMAN, Direct and inverse theorems for certain Bernstein-type operators, J. Comput. Appl. Math., 47 (2) (1993), 267-272.

[10] M. K. KHAN, Approximation at discontinuity, Proceedings of the 4th international conference on functional analysis and approximation theory, Acquafredda di Maratea (Potenza), Italy, September 22-28, 2000: Circolo Matemàtico di Palermo, Suppl. Rend. Circ. Mat. Palermo, II. Ser. 68 (2002), $539-553$.

[11] R. A. KHAN, A note on a Bernstein type operator of Bleimann, Butzer and Hahn, J. Approx. Theory 53 (1988), 295-303.

[12] A. N. ShIRYAYEV, Probability, Springer-Verlag, New York, 1984.

[13] X. M. Zeng And A. Piriou, On the rate of convergence of two Bernstein-Bézier type operators for bounded variation functions, J. Approx. Theory 95 (1998), 369-387.

[14] X. M. ZENG AND F. CHENG, On the rate of approximation of Bernstein type operator, J. Approx. Theory 109 (2001), 242-256. 